\title{
Efeito do Silício no Controle da Cercosporiose em Três Variedades de Cafeeiro*
}

\author{
Adélia A. A. Pozza1, Eduardo Alves², Edson A. Pozza², Janice G. de Carvalho', Marcelo Montanari'1, Paulo \\ T. G. Guimarães ${ }^{3} \&$ Deila M. Santos ${ }^{2}$
}

'Departamento de Ciência do Solo; ${ }^{2}$ Departamento de Fitopatologia, UFLA, Cx. Postal 37, CEP 37200-000, Lavras, MG,

Fax: (35) 3829-1283, e-mail: adelia@ufla.br, ${ }^{3}$ EPAMIG-CTSM, Cx. Postal 176, CEP 37200-000, Lavras, MG

(Aceito para publicação em 06/11/2003)

Autor para correspondência: Adélia A. A. Pozza

POZZA, A.A.A., ALVES, E., POZZA, E.A., CARVALHO, J. G. de, MONTANARI, M., GUIMARÃES, P.T.G. \& SANTOS, D.M. Efeito do silício no controle da cercosporiose em três variedades de cafeeiro. Fitopatologia Brasileira 29:185-188. 2004.

\section{RESUMO}

A cercosporiose do cafeeiro (Coffea arabica), causada por Cercospora coffeicola, é uma das mais importantes doenças na fase de viveiro. O objetivo desse trabalho foi avaliar o efeito da aplicação de silício ( $1 \mathrm{~g}$ de $\mathrm{CaSiO}_{3}$ incorporada em $1 \mathrm{~kg}$ do substrato utilizado para encher os tubetes) no controle dessa doença em três variedades de cafeeiro (catuaí, mundo novo e icatú) e, determinar quais os possíveis fatores de resistência associados. As plantas com dois pares de folhas foram inoculadas com suspensão de 1,4 x $10^{4}$ conídios de $C$. coffeicola por $\mathrm{ml}$. Aos sete meses após a inoculação avaliaram-se a porcentagem de folhas lesionadas e o número total de lesões por planta. Após essa avaliação, retiraram-se amostras das folhas para o estudo em Microscopia Eletrônica de Varredura (MEV) e
Microanálise de Raios-X (MAX). As plantas da variedade catuaí tratadas com silicato, tiveram redução de $63,2 \%$ nas folhas lesionadas e de $43 \%$ no total de lesões por planta, em relação à testemunha. A MAX e o mapeamento para Si indicaram distribuição uniforme do elemento em toda a superfície abaxial das folhas de cafeeiro nas três variedades tratadas. Nas folhas das plantas não tratadas, o Si foi raramente encontrado. Nas imagens de MEV também foi observada camada de cera bem desenvolvida na superfície inferior das folhas originárias de todas as plantas tratadas, sendo esta mais espessa em catuaí e rara ou ausente nas não tratadas.

Palavras-chave adicionais: mancha de olho pardo, Coffea arabica, Cercospora coffeicola, nutrição mineral.

\section{ABSTRACT}

Effect of silicon on the control of brown eye spot in three coffee cultivars

Brown eye spot of coffee (Coffea arabica) is an important nursery disease. The goal of this work was to evaluate the effect of silicon $\left(1 \mathrm{~g}\right.$ of $\mathrm{CaSiO}_{3}$ incorporated in $1 \mathrm{~kg}$ of substrate used to fill the containers) on the control of this disease in three coffee cultivars, catuaí, mundo novo and icatú, and to determine which resistance factors were stimulated. Young plants with two pairs of leaves were inoculated with a suspension containing $1.4 \times 10^{4}$ Cercospora coffeicola conidia. $\mathrm{ml}^{-1}$. Seven months after inoculation the plants were evaluated to determine the percentage of leaves with disease

A cercosporiose ou "mancha-de-olho-pardo", causada por Cercospora coffeicola Berk. \& Cooke, constitui uma das principais doenças da fase de viveiro da cultura do café (Coffea arabica L.). As plantas doentes apresentam desfolha, redução no desenvolvimento e raquitismo, tornando-se impróprias ao plantio (Fernandez-Borrero et al., 1966). O principal método de controle da cercosporiose é o químico. No entanto, uma prática alternativa é manejar a nutrição mineral para aumentar

\footnotetext{
*Parte da Tese de Doutorado da primeira autora. Universidade Federal de Lavras (2004).
}

(\%) and the total number of lesions per plant. Before the evaluation, leaf samples were studied using a scanning electron microscope and $\mathrm{X}$-ray microanalysis. In the catuaí cultivar treated with silicon, ther was a reduction of $63,2 \%$ of leaves with lesions and $43 \%$ of total lesions per plant, in relationship the non-treated plants. X-ray microanalysis and mapping of $\mathrm{Si}$ showed uniform distribution of elements on all abaxial surfaces of leaves in all the treated cultivars. On leaves of non-treated plants, the Si was rare or absent. Scanning electron microscopy also showed a very well developed wax layer on the lower leaf surfaces of all cultivars, but this layer was thicker in the catuaí cultivar and thin or absent in control plants. a resistência à doença (Marschner, 1995).

Dentre os nutrientes minerais utilizados no manejo de doenças o silício destaca-se por reduzir a severidade de importantes doenças em várias culturas (Epstein, 1999). O silício pode atuar na constituição de barreira física de maneira a impedir a penetração de fungos e afetar os sinais entre o hospedeiro e o patógeno, resultando na ativação mais rápida e extensiva dos mecanismos de defesa pré e pós-formados da planta (Chérif et al., 1992; Chérif et al., 1994; Epstein, 1999). Como função estrutural, proporciona mudanças anatômicas nos tecidos, como células epidérmicas com a parede celular 
mais espessa devido à deposição de sílica nas mesmas (Blaich $\&$ Grundh Fer, 1998), favorecendo a melhor arquitetura das plantas, além de aumentar a capacidade fotossintética e resistência às doenças (Bélanger \& Menzies, 2003).

A microanálise de raios $X$ (MAX) é uma técnica utilizada para avaliar e explicar o efeito do silício na resistência das plantas (Lux et al., 2002). Associada a esta, a microscopia eletrônica de varredura (MEV), também pode trazer importantes informações sobre a formação de barreiras físicas à penetração e colonização dos patógenos.

Tendo em vista esses fatores, o objetivo desse trabalho foi avaliar a eficiência do silicato de cálcio no controle da cercosporiose em mudas de três variedades de cafeeiro e estudar por meio da MEV e MAX os mecanismos de resistência envolvidos.

$\mathrm{O}$ experimento foi implantado no viveiro de café da Fazenda Experimental da EPAMIG, Centro Tecnológico do Sul de Minas, Lavras, MG. Foram avaliadas três variedades de café, catuaí vermelho - IAC 99, mundo novo - IAC 379/19 e icatú - IAC 2942. Os tratamentos foram: $1 \mathrm{~g}$ silicato de cálcio $\left(\mathrm{CaSiO}_{3}\right)$ por quilo de substrato e a testemunha, sem silicato. O substrato foi constituído por $80 \%$ de esterco bovino curtido e $20 \%$ de terra de subsolo. As plântulas foram obtidas em germinador de areia lavada e transplantadas para os tubetes no estádio de "palito de fósforo".

$\mathrm{O}$ experimento foi conduzido em delineamento experimental inteiramente casualizado em esquema fatorial de três variedades combinadas com duas adubações (com e sem $\mathrm{Si}$ ) e quatro repetições. As parcelas foram constituídas por 16 tubetes de $120 \mathrm{~cm}^{3}$, considerando-se como parcela útil os seis centrais. Ao atingirem dois pares de folhas definitivas as mudas de cafeeiro foram inoculadas com a suspensão de $1,4 \times 10^{4}$ conídios/ml, segundo metodologia utilizada por Pozza (1999). O número de folhas doentes (\%) e o total de lesões de $C$. coffeicola foram avaliados antes da coleta de amostras para $\mathrm{MEV}$, quando as mudas encontravam-se com sete meses de idade.

A preparação e a observação em MEV (DSM940 Zeiss, acoplado ao sistema de microanálise de raios-X: EDS OXFORD INSTRUMENT Link ISIS) foi realizada no NAP/ MEPA da ESALQ/USP. Para tanto, foram retiradas folhas do terceiro par, de cinco mudas de cafeeiro, dos tratamentos com as doses zero e $1,0 \mathrm{~g}$ de $\mathrm{CaSiO}_{3} / \mathrm{kg}$ de substrato para cada variedade. De cada folha amostrada, foram retirados dois fragmentos do limbo foliar ( $3 \times 3 \mathrm{~mm}$ cada) e preparados para MEV. Os dez espécimes obtidos para cada tratamento foram montados em suportes de alumínio "stubs", com o auxílio de fita adesiva de carbono dupla face, sendo cinco com a face inferior do limbo voltada para cima e cinco para baixo. Em seguida foram cobertos com ouro e observados em MEV. Todos os espécimes montados foram observados e quatro imagens da superfície de cada amostra foram geradas e registradas digitalmente, ao acaso, nas condições de $20 \mathrm{Kv}$ e distância de trabalho de $9 \mathrm{~mm}$. Destas imagens, foram selecionadas duas imagens de cada variedade e preparadas no Software Photopaint? do pacote Corel Draw 9? .
Dez fragmentos, também de $9 \mathrm{~mm}^{2}$, do limbo foliar, das mesmas folhas utilizadas para a observação em MEV, foram preparados para a MAX. Cortaram-se os dez fragmentos, sendo a metade deles montada em suportes de alumínio com a face superior voltada para cima e, a outra metade montada com a face inferior voltada para cima. Estes espécimes foram levados para dessecador contendo sílica gel, onde permaneceram por $24 \mathrm{~h}$. Em seguida, foram levados ao aparelho "sputtering" (MED 010, Balzer) e cobertos com uma fina camada de carbono para serem observados em MEV com distância de trabalho $25 \mathrm{~mm}$ e $20 \mathrm{kv}$. Após análise dos elementos presentes nas amostras, procedeu-se o mapeamento para Si na área analisada, utilizando o Software ISIS? . Imagens de MEV foram também geradas, porém, devido a pior qualidade das mesmas, proporcionadas pela técnica, estas não foram apresentadas neste trabalho.

Foram observadas interações significativas entre as variedades e a presença de silício em relação à intensidade da doença. As plantas da variedade catuaí com silício incorporado ao substrato apresentaram $63,2 \%$ menos folhas lesionadas e $43 \%$ menos lesões, quando comparadas à testemunha. Também houve diferença significativa entre as variedades, a catuaí e a mundo novo apresentaram maior número médio de folhas doentes e lesões por planta do que icatú (Tabela 1). Segundo Matiello \& Almeida (1997), a variedade icatú apresenta maior resistência à cercosporiose. Plantas resistentes à doença apresentam menor resposta à aplicação de silício, dessa forma, a resposta da variedade icatú foi semelhante à proporcionada pelo silício nas variedades catuaí e mundo novo (Tabela 1). Rodrigues et al. (2001) também encontraram menores respostas à aplicação de $\mathrm{CaSiO}_{3}$ nas variedades resistentes, para o controle da rizoctoniose de arroz (Orysa sativa L.) causada por Rhizoctonia solani Khun.

O efeito do Si no controle de doenças em várias culturas foi relatado tanto em mono, quanto em dicotiledôneas. Para o cafeeiro, esse efeito ainda não foi bem elucidado. Os mecanismos pelos quais o silício pode conferir resistência à determinada doença podem ser por acúmulo do elemento na parede das células da epiderme e cutícula, acúmulo no local de penetração do patógeno (barreiras estruturais), ou ativação das barreiras químicas e bioquímicas da planta (Epstein, 1999). Por meio de MEV, observou-se a presença de uma cutícula mais espessa na superfície inferior da folha das plantas tratadas com silício, principalmente devido à camada de cera epicuticular mais desenvolvida. Essa camada de cera epicuticular, em algumas amostras principalmente de catuaí, cobriu parcialmente os estômatos (Figura 1 B, D, F), enquanto nas testemunhas os estômatos puderam ser observados com clareza (Figura $1 \mathrm{~A}, \mathrm{C}, \mathrm{E}$ ). Dentre as variedades, a catuaí apresentou camada de cera epicuticular mais espessa (Figura 1B). Essa camada pode ter tornado a superfície hidrofóbica, impedindo a formação do filme de água, importante para os processos vitais da patogênese como a germinação e a penetração, além de permitir o acúmulo de substâncias antifúngicas na cutícula. Pascholati \& Leite (1985) citaram vários exemplos de patossistemas onde a espessura da cutícula teve efeito sobre a 
Efeito do silício no controle da cercosporiose em três ...

TABELA 1 - Porcentagem de folhas de café (Coffea arabica), lesionadas por Cercospora coffeicola, por planta e total de lesões por planta, nas variedades catuaí, mundo novo e icatú, com e sem aplicação de silicato ao substrato para mudas em tubetes

\begin{tabular}{|c|c|c|c|c|c|c|}
\hline \multirow{2}{*}{ Variedade } & \multicolumn{3}{|c|}{$\begin{array}{c}\text { Folhas lesionadas } \\
\text { por planta }(\%)\end{array}$} & \multicolumn{3}{|c|}{$\begin{array}{c}\text { Total de lesões } \\
\text { por planta }\end{array}$} \\
\hline & $\begin{array}{l}\text { Com } \\
\text { silicato }\end{array}$ & $\begin{array}{c}\text { Sem } \\
\text { silicato }\end{array}$ & Média & $\begin{array}{c}\text { Com } \\
\text { silicato }\end{array}$ & $\begin{array}{c}\text { Sem } \\
\text { silicato }\end{array}$ & Média \\
\hline Catuaí & $16,0 \mathrm{a}$ & $25,3 . b$ & $20,6 \mathrm{~B}$ & $18,8 \mathrm{a}$ & $43,3 \mathrm{~b}$ & $31,1 \mathrm{~B}$ \\
\hline Mundo Novo & $22,9^{\mathrm{ns}}$ & $23,3^{\mathrm{ns}}$ & $23,1 \mathrm{~B}$ & $24,2^{\mathrm{ns}}$ & $30,5^{\mathrm{ns}}$ & $27,4 \mathrm{~B}$ \\
\hline Icatú & $14,5^{\mathrm{ns}}$ & $16,0^{\mathrm{ns}}$ & $15,3 \mathrm{~A}$ & $13,3^{\text {ns }}$ & $21,8^{\text {ns. }}$ & $19,1 \mathrm{~A}$ \\
\hline
\end{tabular}

ns.não significativo. Letras iguais minúsculas nas linhas e maiúsculas na coluna não diferem entre si (Tukey, 5\%).

penetração de fungos. Portanto, a cutícula mais espessa com a camada de cera epicuticular mais desenvolvida observada neste estudo, pode explicar em grande parte a redução no número de lesões de $C$. coffeicola nas variedades mundo novo e catuaí, fato ainda não verificado em outros experimentos com aplicação de silício.

Na MAX nenhuma diferença significativa foi verificada, quanto à presença de silício na superfície superior das folhas e na parte interna do limbo foliar em relação ao controle. Porém, na face inferior das folhas verificou-se maior quantidade de silício nas folhas de plantas tratadas (Figura 2 $\mathrm{B}, \mathrm{D}, \mathrm{F})$ do que nas não tratadas, sendo o silício ausente nestas últimas (Figuras 2A, 2C e 2E). Quando se procedeu ao
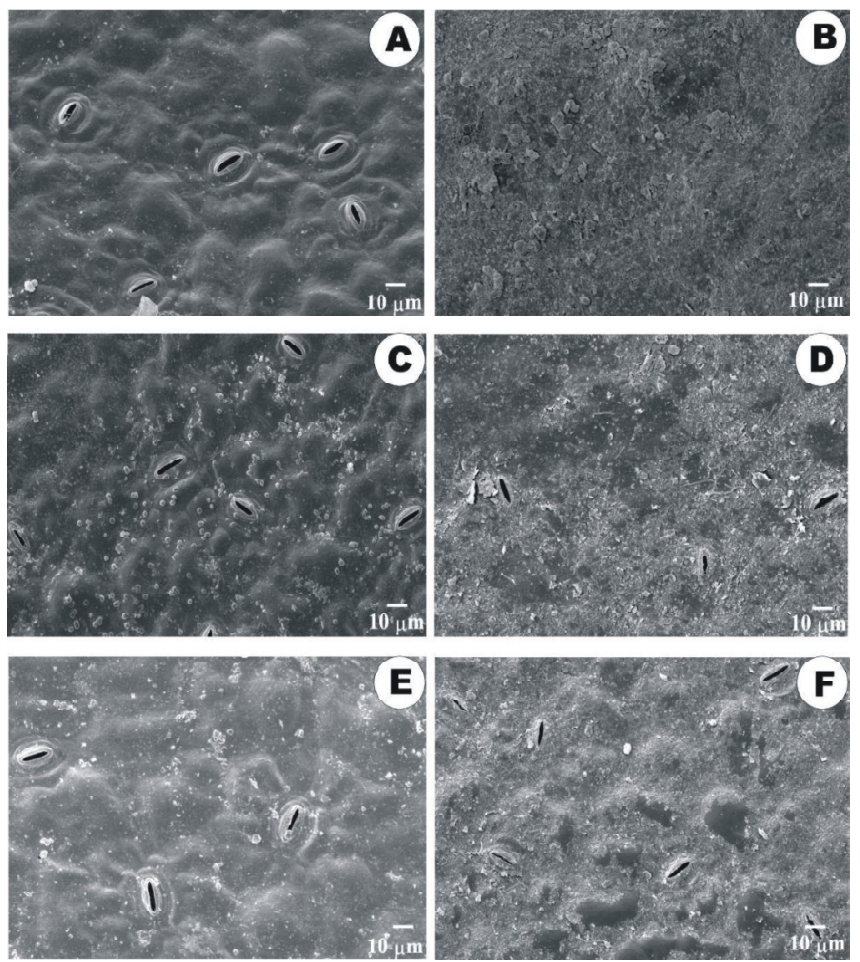

FIG. 1 - Superfície inferior de folhas de plantas de cafeeiro (Coffea arabica) das variedades catuaí (A-B), mundo novo (C-D) e icatú (EF), tratadas com $\mathrm{CaSiO}_{3}(\mathrm{~B}, \mathrm{D}$ e F) e não tratadas $(\mathrm{A}, \mathrm{C}$, e E).
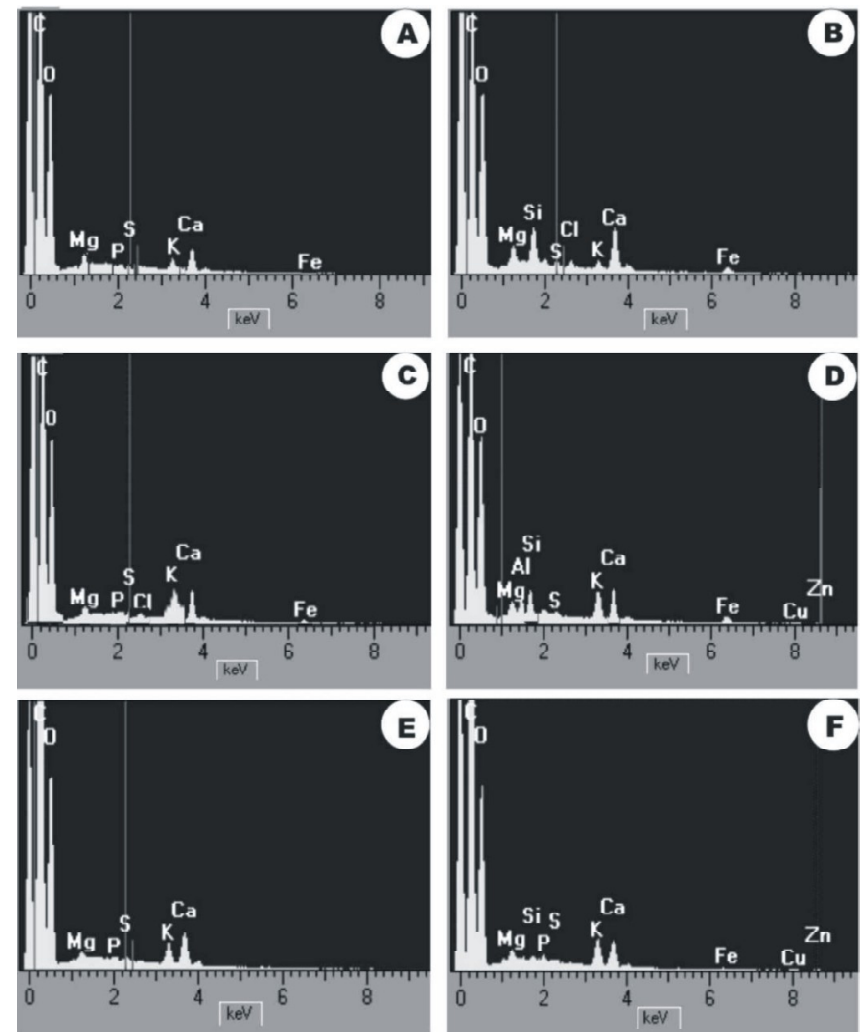

FIG. 2 - Microanálise de raios-X da superfície inferior de folhas das variedades de cafeeiro (Coffea arabica) (A-F) catuaí (A-B), mundo novo (C-D) e icatú (E-F). Microanálise de folhas de planta não tratada (A, C e E) e de folhas de plantas tratadas (B. D e F) com $\mathrm{CaSiO}_{3}$ Escala dos gráficos: Total na vertical $60 \mathrm{cps}$ (Capturas por Segundo).
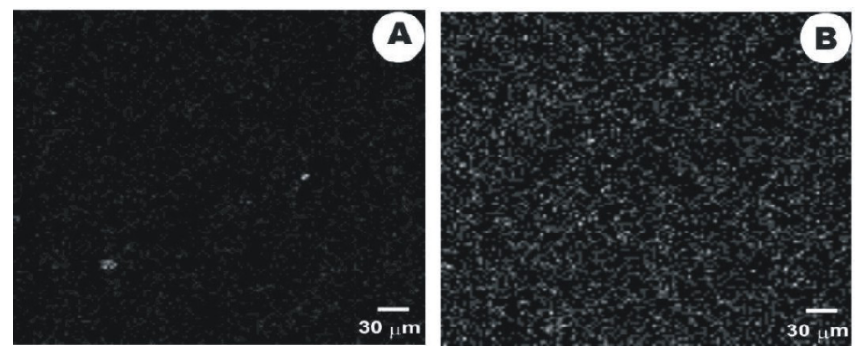

FIG. 3 - Mapeamento para Si da área do limbo foliar de folhas de mudas de cafeeiro (Coffea arabica), variedade catuaí, mostrando uma menor presença e distribuição mais concentrada do elemento em folha de planta não tratada (A) e maior presença e distribuição em folha de planta tratada com $\mathrm{CaSiO}_{3}$ (B).

mapeamento para $\mathrm{Si}$, verificou-se distribuição uniforme do Si na superfície da área analisada das folhas tratadas (Figura 3B). Na testemunha, o Si foi encontrado de forma localizada (Figura 3A).

A polimerização de silício na superfície inferior da folha, processo denominado silicificação, é comum em gramíneas (Lux et al., 2002) e pode ocorrer em dicotiledôneas 
(Epstein, 1999), porém até então não havia sido verificado em cafeeiro. Foi observado através da MAX que o Si encontrava-se posicionado principalmente na epiderme, pois, quando as áreas com pouca cera epicuticular foram analisadas, o teor do elemento foi detectado em menor quantidade. Em corte transversal da folha a quantidade de Si detectada foi mínima e praticamente igual a da testemunha. Em áreas da superfície inferior da folha onde a cutícula foi retirada ainda se verificou a presença de Si quando se procedeu ao mapeamento (dados não apresentados). A presença deste elemento na camada externa da epiderme foi observada por Carver et al. (1987). Esses autores também observaram que a complexação do sílicio com compostos fenólicos na parede das células da epiderme pode reduzir e dificultar a expansão das lesões, bem como a intensidade de doença, por tornar as células mais rígidas, fato verificado mais recentemente por Rodrigues et al. (2001). Essas constatações podem afetar a epidemiologia da doença tanto por reduzir a penetração, quanto por contribuir para menor esporulação do fungo.

Além do Si, as amostras tratadas apresentaram maior quantidade de $\mathrm{Fe}$ e a presença de $\mathrm{Zn}$ e $\mathrm{Cu}$, a qual não foi verificada nas testemunhas (Figuras 2A-2F). Além da ação antifúngica (Marschner, 1995), esses nutrientes podem atuar como co-fatores na síntese de enzimas, inclusive naquelas ligadas a patogênese tornando-se mais uma evidência da atuação destas substâncias no processo de defesa da planta. A maior quantidade desses microelementos pode estar associada à indução da resistência sistêmica (Bélanger \& Menzies, 2003) e contribuir para melhor nutrição das mudas. Essa resistência foi observada em arroz e em pepino (Cucumis sativus L.) devido à produção de fitoalexinas e compostos fenólicos em plantas tratadas com silício (Fawe et al., 1998; Seebold et al., 2000). Outro efeito do silício é o da ativação das defesas químicas e bioquímicas da planta, aumentando o conteúdo de fenóis, a atividade de quitinases, $\beta$-1,3-glucanases, peroxidases, B-glicosidades, fenilamonia liase e polifenoloxidase (Fawe et al., 1998; Rodrigues et al., 2001; Bélanger \& Menzies, 2003) as quais não foram analisadas neste estudo. Essas análises, em trabalhos futuros, poderiam contribuir para explicar a redução do número de lesões nas variedades catuaí e mundo novo.

\section{REFERÊNCIAS BIBLIOGRÁFICAS}

BÉLANGER, R.R. \& MENZIES, J.G. Use of silicon to control diseases in vegetable crops. In: Congresso Brasileiro de Fitopatologia, 36, Uberlândia, Fitopatologia Brasileira 28:S42-S45. 2003. (Resumo)
BLAICH, R. \& GRUNDHÖFER, H. Silicate incrusts induced by powdery mildew in cell walls of diferent plant species. Zeitschift fur Pflanzenkrankheiten und Pflanzenschutz 105:114-120. 1998.

CARVER, T.L.W., ZEYEN, R.J. \& AHLSTRAND, G.G. The relationship between insoluble silicon and success or failure of attempted primary penetration by powdery mildew (Erysiphe graminis) germiling on barley. Physiological and Molecular Plant Pathology 31:133-148. 1987.

CHÉRIF, M., ASSELIN, A. \&.BÉLANGER, R.R. Defense responses induced by soluble silicon in cucumber roots infected by Pythium spp. Phytopathology 84:236-242. 1994.

CHÉRIF, M., BENHAMOU, N., MENZIES, J.G. \& BÉLANGER, R.R. Silicon induced resistance in cucumber plants against Pythium ultimum. Physiological and Molecular Plant Pathology 41:411-425. 1992.

EPSTEIN, E. Silicon. Annual Review of Plant Physiology and Plant Molecular Biology 50:641-664. 1999.

FERNANDEZ-BORRERO, O., MESTRE, A.M. \& DUQUE, S.I.L. Efecto de la fertilizacion en la incidencia de la mancha de hierro (Cercospora coffeicola) en frutos de café. Centro Nacional de Investigaciones de Café 17:5-17. 1966.

FAWE, A., ABOU-ZAID, M., MENZIES, J.G. \& BÉLANGER, R.R. Silicon-mediated accumulation of flavonoid phytoalexins in cucumber. Phytopathology 88:396-401. 1998.

LUX. A., LUXOVA, M., HATTORI, T., INANAGA, S. \& SUGIMOTO, Y. Silicification in sorghum (Sorghum bicolor) cultivars with different drought tolerance. Physiologic Plantarum 115:87-92. 2002.

MARSCHNER, H. Mineral nutrition of higher plants. 2nd ed. New York. Academic Press. 1995.

MATIELLO, J.B. \& ALMEIDA, S.R. Variedades de café - como escolher, como plantar. Rio de Janeiro. MAA/SDR/PROCAFÉ. 1997.

PASCHOLATI, S.F. \& LEITE, B. Hospedeiros: mecanismos de resistência. In: Bergamin Filho, A., Kimati, H. \& Amorin, L. (Eds.) Manual de Fitopatologia - princípios e conceitos. São Paulo. Ceres. 1995. pp.417-453.

POZZA, A.A.A. Influência da nutrição nitrogenada e potássica na intensidade da mancha de olho pardo (Cercospora coffeicola Berk. \& Cook.) em mudas de cafeeiro (Tese de Mestrado). Viçosa. Universidade Federal de Viçosa, 1999.

RODRIGUES, F., DATNOFF, L.E., KORNDÖRFER, G.H., SEEBOLD, K.W. \& RUSH, M.C. Effect of silicon and host resistance on sheath blight development in rice. Plant Disease 85:827-832. 2001.

SEEBOLD, K.W., DATNOFF, L.E., CORREA-VICTORIA, F.J., KUCHAREK, T.A. \& SNYDER, G.H. Effect of silicon rate host resistance on blast, scald, and yield of upland rice. Plant Disease 84:871-876. 2000. 